\title{
RANCANG BANGUN CETAKAN LOGAM UNTUK PRODUK BILAH GAMELAN PADA MESIN HIGH PRESSURE DIE CASTING
}

\author{
Sugeng Slamet \\ Fakultas Teknik, Program Studi Teknik Mesin \\ Universitas Muria Kudus \\ Email: sugeng.slamet@umk.ac.id \\ Setiawan Harmoko \\ Fakultas Teknik, Program Studi Teknik Mesin \\ Universitas Muria Kudus \\ Email: setiawan.harmoko@umk.ac.id
}

\begin{abstract}
ABSTRAK
High Pressure Die Casting/HPDC bertujuan untuk mendapatkan produk cor dengan kepadatan dan kepresisian yang tinggi. Salah satu bagian terpenting dari pengecoran adalah cetakan. Besarnya tekanan HPDC yang besar membutuhkan cetakan permanen yang terbuat dari logam dan mampu menerima tegangan tanpa mengalami deformasi. Bilah gamelan selama ini dikerjakan dengan pengecoran konvensional dilanjutkan dengan tempa tangan. Besarnya energi tempa serta lamanya waktu pengerjaan menjadi penyebab produktifitas rendah. Inovasi teknik produksi menggunakan teknik high pressure die casting diharapkan mampu mengatasi permasalahan tersebut. Metode yang dilakukan adalah merancang dan membuat cetakan bilah gamelan dari bahan logam. Tahapan perancangan dimulai dari membuat desain, menentukan bahan logam, menghitung dimensi cetakan, kecepatan alir logam cair, tekanan pada rongga cetakan dan laju perpindahan panas pada dinding cetakan. Cetakan logam berbahan AISI H13 untuk produk bilah gamelan yang dipasang pada mesin HPDC. Hasil perhitungan volume rongga cetakan $180630,786 \mathrm{~mm}^{3}$, kecepatan alir $0,5638 \mathrm{~m} / \mathrm{s}$, tekanan rongga cetakan $8385610,98 \mathrm{~Pa}$ dan temperatur dinding cetakan rata-rata $150^{\circ} \mathrm{C}$.
\end{abstract}

Kata kunci: HPDC, bilah gamelan, cetakan permanen, AISI H13

\section{ABSTRACT}

High Pressure Die Casting / HPDC aims to get cast products with high density and precision. One of the most important parts of casting was mold. The large HPDC pressure requires a permanent mold made of metal and was able to accept stress without deformation. The gamelan blade has been done with conventional casting followed by hand forgings. The amount of forging energy and the length of processing time were the causes of low productivity. Production engineering innovations using high pressure die casting techniques were expected to be able to overcome these problems. The method used was to design and make molds of gamelan blades from metal. The design stage starts from making design, determining the metal material, calculating the dimensions of the mold, the velocity of the liquid metal, the pressure on the mold cavity and the rate of heat transfer on the mold wall. AISI H13 metal mold for the gamelan blade product installed on the HPDC machine. The results of the calculation of the mold cavity volume were $180630,786 \mathrm{~mm}^{3}$, the flow velocity was $0.5638 \mathrm{~m} / \mathrm{s}$, the mold cavity pressure was $8385610.98 \mathrm{~Pa}$ and the average wall mold temperature was $150^{\circ} \mathrm{C}$.

Keywords: HPDC, gamelan blades, permanent mold, AISI H13

\section{PENDAHULUAN}

Cetakan merupakan bagian penting dalam teknik pengecoran logam untuk menghasilkan produk cor sesuai yang diinginkan. Bahan cetakan dapat menggunakan pasir, logam, kayu, plastik 
dan sejenisnya. Cetakan terdiri atas 2 bagian yaitu cetakan bawah (drag) dan cetakan atas (cope). Bagian drag maupun cope disatukan sebelum memulai pengecoran. Cetakan dibuat sesuai dengan pola dari produk yang akan dibuat. Pola menghubungkan antara cetakan dan produk benda cor. Pola dapat dibuat secara permanen dengan menggunakan logam dan kayu, sedangkan pola non permanet dibuat menggunakan styrofoam maupun lilin [1].

Cetakan logam merupakan cetakan permanen yang digunakan untuk menghasilkan benda cor secara berulang. Cetakan logam akan menghasilkan produk cor yang lebih ekonomis baik dari sisi kualitas maupun kuantitas. Cetakan logam dirancang tidak saja sesuai dengan bentuk benda kerja, akan tetapi harus memperhatikan karakteristik logam cor dan perlakuan cetakan. Cetakan pada mesin high pressure die casting biasanya dikenai pre heating dan tekanan yang cukup besar. Cetakan logam dipastikan tidak mengalami deformasi dan pecah saat menerima panas dan tekanan. Cetakan logam yang terpasang pada mesin HPDC terdiri dari dua bagian yaitu bagian tetap dan bagian bergerak. Bagian bergerak dapat membuka dan menutup sepanjang batas vertikal sehingga produk cor mudah dikeluarkan dari cetakan. Cetakan permanen dapat menggantikan bahan pasir dan keramik untuk menghasilkan produk dengan presisi dan konsisten dalam bentuk dan ukuran [2].

Logam yang digunakan untuk membuat cetakan adalah baja paduan dan harus memiliki syaratsyarat antara lain memiliki dimensi yang stabil, ketahanan dan ketangguhan yang baik. Baja dengan kandungan karbon tinggi mempunyai kekuatan dan kekerasan yang tinggi, namun keuletannya menurun. Kemampuannya untuk dikeraskan (hardenability) meningkat dengan semakin tingginya kadar karbon. Bahan logam untuk cetakan dibuat dari besi cor ductile [3], besi cor kelabu yang dikeraskan [4]. Baja karbon sedang 0,25-0,55\% lebih kuat, dapat dikeraskan serta banyak digunakan sebagai baja konstruksi mesin dan cetakan logam [5]. AISI H13 adalah jenis baja yang dikenal pemakaiannya untuk proses pengerjaan pada temperatur tinggi seperti cetakan pada proses pengecoran die casting.

Gamelan merupakan seperangkat alat musik yang terbuat dari bahan logam, khususnya logam non ferro yaitu kuningan dan perunggu. Gamelan mempunyai keistimewaan pada aspek audio dan visual. Keistimewaan pada audio meliputi : warna bunyi (tone colour), laras (scale system), embat interval dan pelayangan ( sound wave), sedangkan keistimewaan pada visualnya meliputi : bentuk, konstruksi, keindahan material yang dipakai, ornamennya [6]. Seperangkat gamelan tersebut salah satunya dinamakan saron. Alat ini berbentuk bilahan dengan enam bilah (satu oktaf) ditumpangkan pada bingkai kayu yang berfungsi sebagai resonator. Gambar 1. menunjukkan bilah saron gamelan.

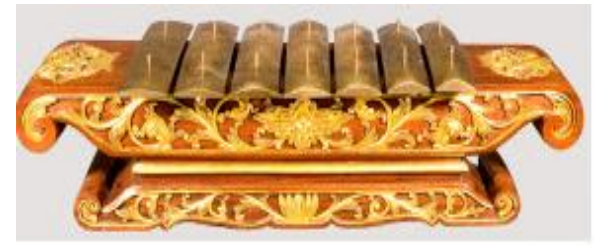

Gambar 1. Bilah saron gamelan Jawa

Teknik manufaktur melalui pengecoran logam terus mengalami perkembangan. High Pressure Die Casting/HPDC merupakan teknik pengecoran logam non konvensional yang bertujuan untuk mendapatkan kerapatan tinggi. Teknik HPDC dilakukan dengan cara memasukkan logam cair ke dalam cetakan dengan cara ditekan. Teknik pengecoran HPDC dapat mengurangi porositas produk logam cor [7]. HPDC mampu menggantikan teknik tempa manual forging untuk membuat produk gamelan [8]. Teknik pengecoran logam HPDC sesuai untuk logam dengan temperatur lebur tinggi seperti paduan aluminum dan paduan tembaga [9]. Sifat mekanis logam cor dapat ditingkatkan dengan memperbaiki struktur mikro paduan melalui mekanisme pembekuan searah [10], dan heat treatment annealing pasca pengecoran [11]. Gambar 2. menunjukkan mesin High Pressure Die Casting/HPDC. 


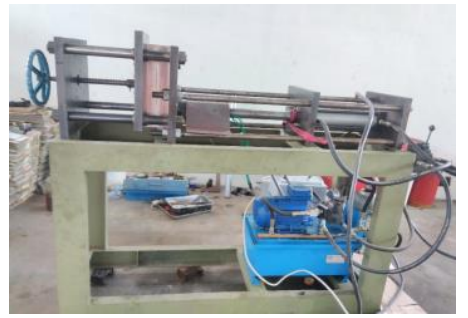

Gambar 2. Mesin High Pressure Die Casting/HPDC

\section{METODOLOGI PENELITIAN}

Rancang bangun cetakan logam untuk produk bilah gamelan ini diawali dengan mengukur dimensi bilah gamelan pada ukuran sebenarnya. Hasil pengukuran tersebut selanjutnya digambar untuk mendapatkan desain yang tepat. Adapun tahapan dalam rancang bangun bilah gamelan adalah sebagai berikut:

a. Mengukur produk bilah gamelan sebenarnya

b. Menggambar desain bilah gamelan

c. Menentukan material cetakan

d. Menghitung dimensi cetakan bilah gamelan

e. Menggambar cetakan bilah gamelan untuk mesin HPDC

f. Menghitung laju perpindahan panasnya

Material dies yang digunakan yaitu baja perkakas Bohler W302 temasuk baja standart AISI H13. Batasan komposisi kimia menurut AISI H13 ditunjukkan pada Tabel 1.

Tabel 1. Komposisi kimia menurut AISI H13

\begin{tabular}{ccccccccc}
\hline AISI & $\mathrm{C}$ & $\mathrm{Si}$ & $\mathrm{Mn}$ & $\mathrm{V}$ & $\mathrm{Ni}$ & $\mathrm{Cr}$ & $\mathrm{Mo}$ & $\mathrm{W}$ \\
\hline \multirow{2}{*}{$\mathrm{H} 13$} & $0.32-$ & \multirow{2}{*}{$0.8-1.2$} & \multirow{2}{*}{$0.4 \mathrm{Max}$} & \multirow{2}{*}{$0.8-1.2$} & - & $4.5-$ & $1-$ & \\
& 0.42 & & & & & \\
& & & & &
\end{tabular}

Batasan komposisi kimia pada produk baja Bohler W302 ditunjukkan pada Tabel 2.

Tabel 2. Komposisi kimia menurut Bohler W302

\begin{tabular}{cccccccc}
\hline $\mathrm{C}$ & $\mathrm{Si}$ & $\mathrm{Mn}$ & $\mathrm{V}$ & $\mathrm{Ni}$ & $\mathrm{Cr}$ & $\mathrm{Mo}$ & $\mathrm{W}$ \\
\hline 0.40 & 1.0 & 0.49 & 0.96 & - & 5.13 & 1.24 & - \\
\hline
\end{tabular}

Dimensi bilah gamelan hasil pengukuran mempunyai panjang $187 \mathrm{~mm}$, lebar $41 \mathrm{~mm}$ dan tebal $26 \mathrm{~mm}$, sebagaimana ditunjukkan pada Gambar 3.
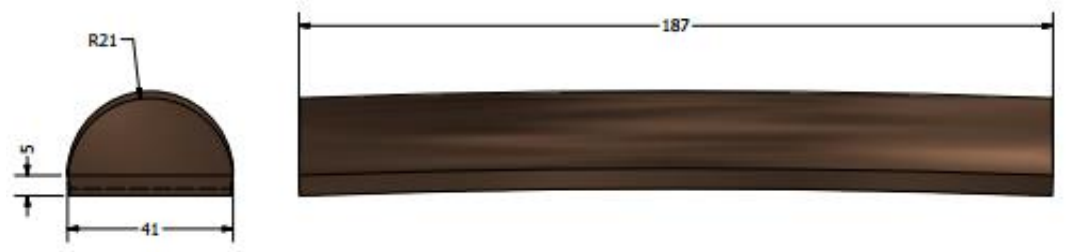

Gambar 3. Dimensi bilah gamelan

Perencanaan runner diperlukan untuk jalan masuk logam cair ke dalam cetakan. Penempatan gate diatur sesuai lebar dimensi bilah sehingga aliran logam cair terdistribusi merata ke seluruh cetakan. Perencanaan cetakan dilakukan dengan menghitung beberapa bagian:

a. Dimensi rongga cetakan meliputi lima bagian yaitu : volume biscuit, volume runner, volume cavity dan volume overflow.

b. Sistem cetakan meliputi kecepatan alir dan tekanan kerja pada rongga cetakan. 
c. Laju perpindahan panas untuk mengetahui distribusi temperatur pada cetakan ketika logam cair di dalam cetakan. Pengujian dilakukan pada temperatur tuang $1100^{\circ} \mathrm{C}$ dan temperatur lingkungan $32^{\circ} \mathrm{C}$.

Proses pemesinan pada cetakan logam untuk bilah gamelan meliputi:

a. Pemotongan logam AISI H13 panjang $300 \mathrm{~mm}$, lebar $=230 \mathrm{~mm}$, tebal $=50 \mathrm{~mm}$ menggunakan Las acetylene.

b. Meratakan permukaan depan dan samping logam AISI H13 setelah pemotongan. Proses permesinan menggunakan pahat end mill berdiameter $40 \mathrm{~mm}$.

c. Permesinan CNC milling digunakan untuk membuat kontour bilah gamelan sesuai desain.

d. Perakitan cetakan dengan base flat pada mesin HPDC.

Proses perataan bahan logam untuk cetakan dan permesinan kontour bilah gamelan ditunjukkan pada Gambar 4.

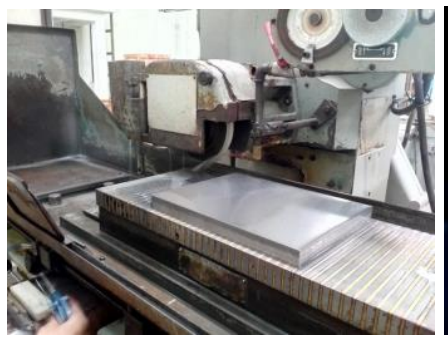

(a)

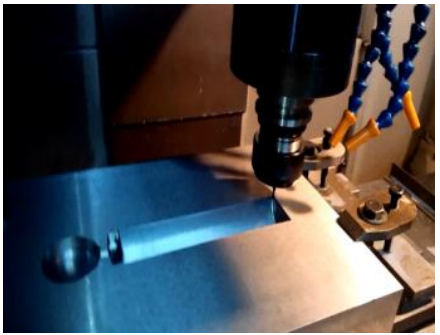

(b)

Gambar 4. (a) Perataan logam bahan cetakan (b) permesinan kontour bilah gamelan

Cetakan logam yang terdiri atas cope dan drag dirakit pada base flat pada mesin HPDC. Base flat, cope dan drag ditunjukkan Gambar 5 dan 6.

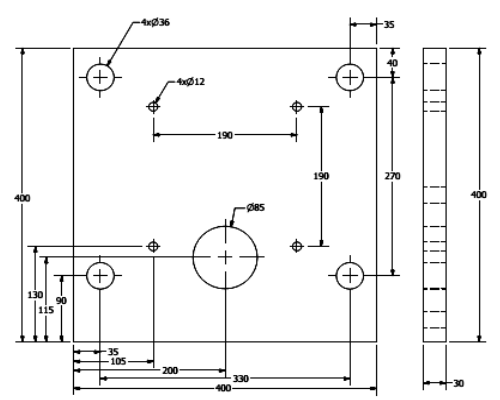

(a)
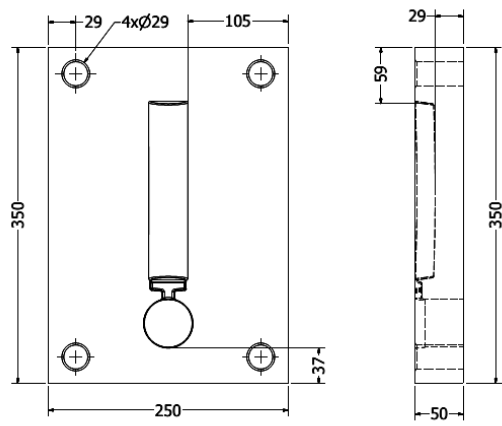

(b)

Gambar 5. (a) base plat fixed (b) Cetakan fixed

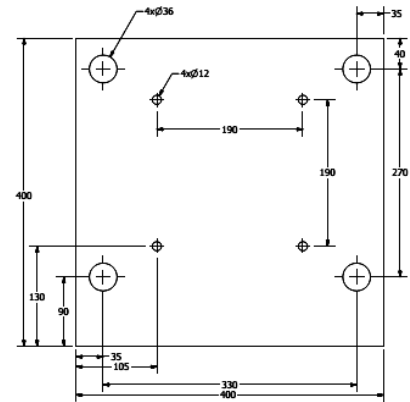

(a)
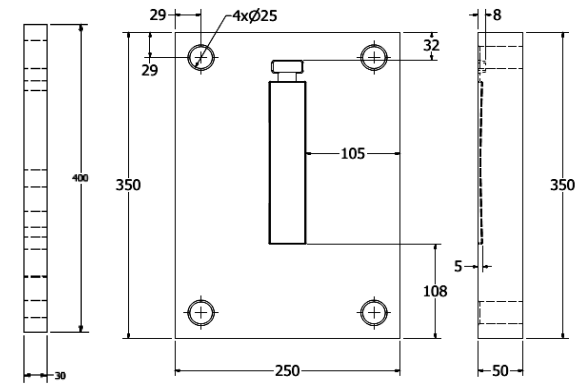

(b)

Gambar 6. (a) base plat moved (b) Cetakan moved 


\section{HASIL DAN PEMBAHASAN}

Perencanaan cetakan logam untuk produksi bilah gamelan harus dapat memastikan logam cair dapat mengalir dan mengisi penuh rongga cetakan. Gambar 7. menunjukkan setiap bagian dari cetakan bilah gamelan yang diinginkan.

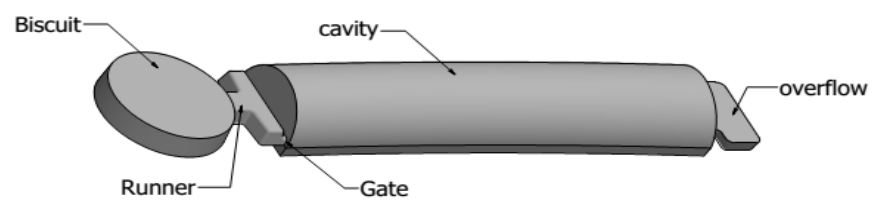

Gambar 7. Desain bilah gamelan

Perhitungan volume pada setiap bagian dari cetakan bilah sebagaimana ditunjukkan Gambar 7 meliputi :

a. Volume Biscuit

Biscuit yang direncanakan berbentuk cone (kerucut yang terpotong). Bentuk tersebut untuk memudahkan dalam mengeluarkan benda cor. Gambar 8. Menunjukkan dimensi biscuit.

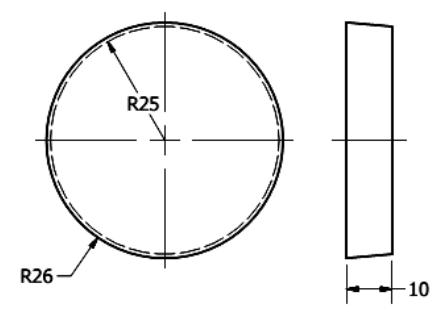

Gambar 8. Dimensi Biscuit

Volume kerucut terpancung :

$$
\begin{aligned}
\mathrm{V} & =1 / 3 \times \pi . t\left(\mathrm{R}^{2}+\mathrm{r} \cdot \mathrm{R}+\mathrm{r}^{2}\right) \\
& =1 / 3 \times 3,14 \times 10 \times\left(26^{2}+25.26+25^{2}\right) \\
& =20297,786 \mathrm{~mm}^{3}
\end{aligned}
$$

\section{b. $\quad$ Volume Runner}

Bentuk penampang dari runner yang direncanakan berbentuk trapesium, sebagaimana ditunjukkan Gambar 9.

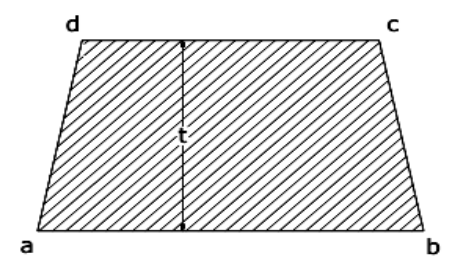

Gambar 9. Dimensi runner

Keterangan gambar : panjang $\mathrm{ab}=13 \mathrm{~mm} ; \mathrm{cd}=10 \mathrm{~mm} ; \mathrm{t}=8 \mathrm{~mm} ; \mathrm{P}=24 \mathrm{~mm}$ ( panjang runner ).

$$
\text { Luas }=1 / 2 \times(a b+c d) \times t
$$




$$
\begin{aligned}
& =1 / 2 \times(13+10) \times 8 \\
& =92 \mathrm{~mm}^{2}
\end{aligned}
$$

Volume $=$ Luas penampang $\mathrm{x}$ panjang

$$
\begin{aligned}
& =92 \times 24 \\
& =2208 \mathrm{~mm}^{3}
\end{aligned}
$$

Jadi volume runner adalah $2208 \mathrm{~mm}^{3}$

c. Volume Produk (bilah)

Perhitungan volume dibagi menjadi dua bagian yaitu volume setengah tabung dan volume balok seperti Gambar 10.
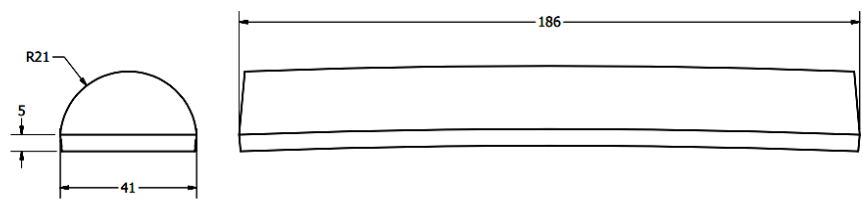

Volume Setengah Tabung $\left(\mathrm{V}_{1}\right)$

$$
\begin{aligned}
\mathrm{V}_{1} & =1 / 2 \times \pi \times \mathrm{r}^{2} \times 1 \\
& =1 / 2 \times 3,14 \times 20^{2} \times 186 \\
& =116180 \mathrm{~mm}^{3}
\end{aligned}
$$

Gambar 10. Dimensi bilah

Volume Balok $\left(\mathrm{V}_{2}\right)$

$$
\begin{aligned}
\mathrm{V}_{2} & =\mathrm{p} \times 1 \times \mathrm{t} \\
& =185 \times 41 \times 5 \\
& =37925 \mathrm{~mm}^{3}
\end{aligned}
$$

Volume keseluruhan bilah $=\mathrm{V}_{1}+\mathrm{V}_{2}$

$$
\begin{aligned}
& =116180 \mathrm{~mm}^{3}+37925 \mathrm{~mm}^{3} \\
& =154105 \mathrm{~mm}^{3}
\end{aligned}
$$

\section{d. Volume Overflow}

Bentuk penampang dari overflow yang direncanakan berbentuk trapesium, ditunjukkan Gambar 11.

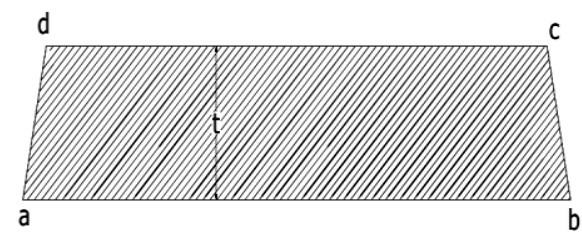

Gambar 11. Dimensi overflow

Keterangan gambar ; panjang $\mathrm{ab}=35 \mathrm{~mm} ; \mathrm{cd}=32 \mathrm{~mm} ; \mathrm{t}=8 \mathrm{~mm}$ dan $\mathrm{P}=15 \mathrm{~mm}$ (panjang overflow )

$$
\begin{aligned}
\text { Luas }= & 1 / 2 \times(a b+c d) \times t \\
& =1 / 2 \times(35+32) \times 8 \\
& =265 \mathrm{~mm}^{2}
\end{aligned}
$$


Volume $=$ Luas penampang $\mathrm{x}$ panjang

$$
\begin{aligned}
& =265 \times 15 \\
& =4020 \mathrm{~mm}^{3}
\end{aligned}
$$

Total volume rongga cetakan $=$ Volume biscuit + Volume runner + volume produk + volume overflow

$$
\begin{aligned}
& =20297,786 \mathrm{~mm}^{3}+2208 \mathrm{~mm}^{3}+154105 \mathrm{~mm}^{3}+4020 \mathrm{~mm}^{3} \\
& =180630,786 \mathrm{~mm}^{3} .
\end{aligned}
$$

Pada Gambar 12. menunjukkan bagian dari cetakan bilah gamelan dan assembling pada HPDC.



(a)

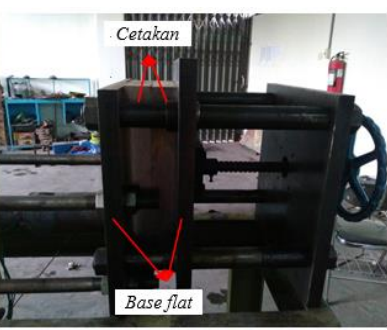

(b)

Gambar 12. (a) Bagian dari cetakan bilah gamelan (b) Pemasangan cetakan pada mesin HPDC

\section{Kecepatan aliran logam pada lubang runner}

$A_{1} \times V_{1}=A_{2} \times V_{2}$

Dimana,

$\mathrm{A}_{1}=$ Luas lubang biscuit $0,625\left(\mathrm{~m}^{2}\right)$

$\mathrm{V}_{1}=$ Kecepatan piston pada saat maju $0,083(\mathrm{~m} / \mathrm{s})$

$\mathrm{A}_{2}=$ Luas lubang runner $0,092\left(\mathrm{~m}^{2}\right)$

maka,

$\mathrm{A}_{1} \times \mathrm{V}_{1}=\mathrm{A}_{2} \times \mathrm{V}_{2}$

$0,625 \times 0,083=0,092 \times \mathrm{V}_{2}$

$0,051875=0,092 \mathrm{~V} 2$

$\mathrm{V} 2=0,5638 \mathrm{~m} / \mathrm{s}$

\section{Tekanan pada rongga cetakan}

$\mathrm{P}_{1}+1 / 2 \rho \mathrm{V}_{1}^{2}+\rho \mathrm{gh}=\mathrm{P}_{2}+1 / 2 \rho \mathrm{V}_{2}^{2}+\rho \mathrm{gh}$

dimana,

$\mathrm{P}_{1}=$ tekanan piston 75,4 $(\mathrm{KPa})=75400(\mathrm{~Pa})$

$\mathrm{V}_{1}=$ Kecepatan piston pada saat maju $0,083(\mathrm{~m} / \mathrm{s})$

$\mathrm{V}_{2}=$ Kecepatan cairan logam pada lubang runner $0,5638(\mathrm{~m} / \mathrm{s})$

$\mathrm{h}_{1}=0(\mathrm{~m})$

$\mathrm{h}_{2}=0,07(\mathrm{~m})$

$\mathrm{g}=9,81 \mathrm{~m} / \mathrm{s}^{2}$

$\rho=$ Massa jenis logam, misalnya perunggu $=8666\left(\mathrm{~kg} / \mathrm{m}^{3}\right)$

maka,

$75400+1 / 2 \times 8666 \times 0,083^{2}+8,666 \times 0 \times 9,81=\mathrm{P}_{2}+1 / 2 \times 8,666 \times 0,5638^{2}+8666 \times 9,81 \times 0,07$

$83931,15=\mathrm{P}_{2}+7504.02$

$\mathrm{P}_{2}=83931,15-7504.02$ 


$$
\mathrm{P}_{2}=8385610.98 \mathrm{~Pa}
$$

\section{Tebal Dies sebagai berikut :}

$\mathrm{P}=$ tekanan pada cetakan $\times \mathrm{S}_{f}(2,5)$

$$
\begin{aligned}
& =8385610.98 \times 2,5=20964027.45 \mathrm{~Pa} \\
& =20.96 \mathrm{~N} / \mathrm{mm}^{2}
\end{aligned}
$$

- Tegangan tarik material baja AISI H13 $(\sigma)=1650 \mathrm{~N} / \mathrm{mm}^{2}$

- Lebar bilah saron $\quad=41 \mathrm{~mm}$

- Tinggi $\quad=20 \mathrm{~mm}$

Untuk mengetahui gaya yang bekerja = intensitas tekanan $\mathrm{x}$ daerah proyeksi

$$
=\mathrm{P} \times(\mathrm{p} \times 1 \times \mathrm{t})
$$

- Tekanan total yang bekerja pada dinding dies

$$
=\sigma \times 2 \mathrm{~T} \times 1 \times \mathrm{t}
$$

Dari persamaan 8 dan 9 , didapatkan persamaan berikut :

$$
\begin{aligned}
& \mathrm{P} \times(\mathrm{p} \times 1 \times \mathrm{t})=\sigma \times 2 \mathrm{~T} \times 1 \times \mathrm{t} \\
& \sigma=\frac{P x(p x l x t)}{2 T x l x t} \\
& \sigma=\frac{P x p}{2 \mathrm{t}} ; \mathrm{t}=\frac{P x p}{2 \sigma}
\end{aligned}
$$$$
\mathrm{t}=25 \mathrm{~mm}
$$

Laju perpindahan panas dihitung dengan mencari selisih antara termperatur tuang logam cair dengan temperatur lingkungan dibagi dengan sejumlah tahanan [12]. Analogi laju perpindahan panas pada cetakan ditunjukkan Gambar 13.

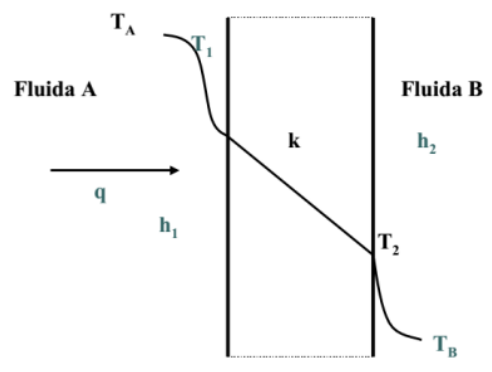

Gambar 13. Analogi perpindahan panas pada cetakan logam

Merujuk laju perpindahan panas pada Gambar 13, jaringan tahanan ditunjukan Gambar 14.



Gambar 14. Jaringan tahanan pada cetakan logam

Persamaan empiris laju perpindahan panas dihitung dengan jalan membagi beda suhu menyeluruh dengan jumlah tahanan dinyatakan dengan persamaan: 


$$
\begin{aligned}
& q=\frac{T_{A}-T_{B}}{\frac{1}{h_{1} A_{1}}+\frac{\Delta x}{k A}+\frac{1}{h_{2} A_{2}}} \\
& q=\frac{1100-32}{37,456+0,0207+4,6620} \\
& q=25,346 \mathrm{~W}
\end{aligned}
$$

Asumsi temperatur tuang logam perunggu $1100^{\circ} \mathrm{C}$ dan temperatur lingkungan $32^{\circ} \mathrm{C}$ didapatkan temperatur diluar dinding cetakan setara $\pm 150^{\circ} \mathrm{C}$. Pengujian cetakan logam untuk produk bilah gamelan pada mesin HDPC mampu mencetak bilah gamelan dengan sempurna. Gambar 15 . menunjukkan produk bilah gamelan pada mesin HPDC.
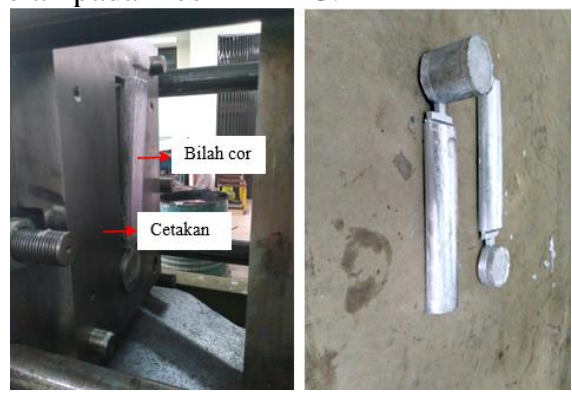

Gambar 15. Produk bilah gamelan pada mesin HPDC

\section{KESIMPULAN}

Perancangan dan proses manufaktur cetakan logam untuk memproduksi bilah gamelan pada mesin high pressure die casting dapat ditarik kesimpulan sebagai berikut:

1. Telah dirancang cetakan logam untuk memproduksi bilah gamelan dengan dimensi tebal dinding cetakan $50 \mathrm{~mm}$, volume rongga cetakan 180630,786 $\mathrm{mm}^{3}$, tekanan kerja pada cetakan $8385610.98 \mathrm{~Pa}$ dan temperatur dinding cetakan pada sisi luar $150^{\circ} \mathrm{C}$.

2. Manufaktur cetakan bilah gamelan meliputi pemotongan material, grinding dan CNC milling untuk membuat kontour bilah gamelan..

3. Pengujian cetakan menggunakan mesin high pressure die casting (HPDC) dengan tekanan $150 \mathrm{~kg} / \mathrm{cm}^{2}$, temperatur tuang $1100^{\circ} \mathrm{C}$ mampu menghasilkan bilah gamelan.

\section{UCAPAN TERIMA KASIH}

Terima kasih atas bantuan biaya penelitian yang diberikan oleh Kemristek DIKTI melalui program hibah penelitian skim hibah bersaing tahun 2016.

\section{DAFTAR PUSTAKA}

[1] W. Everhart, S. Lekakh., V. Richards, J. Chen., H.Li, 2013, Corner strength of investment casting shells, International journal of metalcasting winter, pp. 21- 27.

[2] Suyitno., dkk, 2016, Aplikasi cetakan permanent untuk meningkatkan produksi dan kualitas produk IKM pengecoran logam kuningan di Ngawen, Sidokarto, Godean, Yogyakarta, Indonesian Journal of Community Engagement, Vol.02, No.01, 66-79.

[3] Cahyo Utomo, 2017, Perencanaan dan pembuatan dies permanent mold pengecoran logam dengan material besi cor ductile (FCD), Skripsi, Universitas Muhammadiyah Surakarta.

[4] Yulianto, A, 2016, Pengecoran besi cor kelabu dengan menggunakan cetakan besi cor ulet yang telah dipanaskan, Skripsi, UNS, Surakarta. 
[5] Suarsana, K, 2017, Diktat ilmu material teknik, Progdi Teknik Mesin, Universitas Udayana, Denpasar.

[6] Hartono, 2011, Perkembangan estetika musikal seni karawitan Jawa dan pengaruhnya terhadap masyarakat pendukungnya, Jurusan seni dan desain Fakultas sastra, Universitas Negeri Malang.

[7] Campbell, J., dan Harding, R.A., 2003, The Fluidity of molten metals 3205 the fluidity of molten metals, TALAT Lecture 3205, University of Birmingham, pp. 1-19

[8] S. Slamet, Sukis., M., Hidayat., T., 2016, Perancangan mesin high pressure die casting untuk memproduksi produk gamelan, Prosiding SNATIF ke-3 Universitas Muria Kudus, ISBN : 978-602-1180-33-4 pp.387-398.

[9] Harjanto dan Suyitno, 2008, Pengaruh temperatur tuang dan temperatur cetakan pada high pressure die casting (HPDC) berbentuk piston paduan Aluminium Silikon, Tesis, Universitas Gadjah Mada, Yogyakarta.

[10] S. Slamet, 2007, Pengaruh konsentrasi Cu pada proses pembekuan searah (unidirectional solidification) paduan Al-Cu, Tesis, Universitas Gadjah Mada, Yogyakarta.

[11] Sukoco, 2011, Annealing pada bilah perunggu gamelan untuk mengurangi retak dan sifat keras, Teknik mesin - Universitas Janabadra, Yogyakarta.

[12] Holman, J.P., "Heat Transfer", sixth edition, McGraw Hill, Ltd., New York, 1986. 